\title{
Resistance to Leaf Rust, Stripe Rust, and Stem Rust in Aegilops spp. in Israel
}

\author{
Y. Anikster and J. Manisterski, Institute for Cereal Crops Improvement, Tel Aviv University, Ramat Aviv 69978, \\ Israel; D. L. Long, United States Department of Agriculture-Agricultural Research Service, Cereal Disease Labora- \\ tory, University of Minnesota, St. Paul 55108; and K. J. Leonard, Plant Pathology Department, University of Min- \\ nesota, St. Paul 55108
}

\begin{abstract}
Anikster, Y., Manisterski, J., Long, D. L., and Leonard, K. J. 2005. Resistance to leaf rust, stripe rust, and stem rust in Aegilops spp. in Israel. Plant Dis. 89:303-308.

In all, 1,323 single plant accessions of Aegilops bicornis, A. kotschyi, A. longissima, A. ovata, A. searsii, A. sharonensis, A. speltoides, and A. variabilis collected from 18 regions in Israel and 2 adjacent regions in Lebanon and Egypt were evaluated for leaf rust (Puccinia triticina) and stripe rust ( $P$. striiformis) resistance in field plots and for seedling resistance to leaf rust and stem rust $(P$. graminis f. sp. tritici) in greenhouse tests. Nearly all accessions of $A$. speltoides were highly resistant to leaf rust, stripe rust, and stem rust. A. longissima and A. ovata were highly resistant to stripe rust, whereas A. bicornis and A. kotschyi were highly susceptible. A. searsii was highly susceptible to stem rust, but 24 to $51 \%$ of accessions of A. bicornis, A. longissima, $A$. ovata, and A. variabilis were resistant to stem rust. Except for A. ovata and A. speltoides, more than $95 \%$ of the Aegilops accessions were susceptible to leaf rust caused by $P$. recondita alternating on Anchusa spp. Only Aegilops ovata was susceptible to P. recondita from Echium spp. A. bicornis, A. koschyi, and A. searsii were highly susceptible as seedlings to common wheat leaf rust caused by $P$. triticina. Most accessions of A. variabilis and about half of the accessions of A. longissima had good seedling resistance to $P$. triticina. Few accessions of $A$. ovata showed seedling resistance to the $P$. triticina population in Israel, but $30 \%$ were resistant to U.S. isolates. In field tests, A. bicornis showed high susceptibility to common wheat leaf rust, but more than $90 \%$ of the accessions of the other Aegilops spp. developed little or no leaf rust on adult plants. The Aegilops spp. in Israel and adjoining countries provide a rich and varied source of rust resistance for wheat breeding.
\end{abstract}

Additional keywords: wild wheat
Rusts are among the most important diseases of common bread wheat (Triticum aestivum) throughout most of the world's wheat-producing regions (24). The three widely distributed wheat rust fungi are Puccinia graminis f. sp. tritici (stem rust), $P$. striiformis (stripe rust), and $P$. triticina (leaf rust). In addition, a form of $P$. recondita found in Morocco and the Iberian Peninsula causes another leaf rust disease of durum wheat (T. turgidum). Other forms of $P$. recondita cause leaf rust on wild relatives of wheat in the genus Aegilops (2). Most rust resistance in wheat and other small grains is race specific and its effectiveness has been short-lived when used in predominant cultivars. The supply of rust resistance genes in known wheat cultivars and land races has been largely exhausted, but wild relatives of wheat are a rich and

Corresponding author: K. J. Leonard

E-mail: kurtl@umn.edu

Accepted for publication 25 October 2004.

DOI: 10.1094/PD-89-0303

This article is in the public domain and not copyrightable. It may be freely reprinted with customary crediting of the source. The American Phytopathological Society, 2005. relatively little-used source of additional resistance genes $(7,14,22)$.

The use of wild relatives of crops as sources of disease resistance may be limited by low fertility in intercrossing with crop species and by difficulties in breaking unfavorable linkages between resistance genes and agronomically undesirable traits. Among species of Aegilops, those with $\mathrm{S}$ or $\mathrm{D}$ genomes are regarded as the most readily available sources for resistance to diseases and insects for transfer to wheat $(7,12)$. Common bread wheat, a hexaploid, has three genomes, A, B, and D. The $\mathrm{B}$ genome is closely related to the $\mathrm{S}$ genome of the Sitopsis group of Aegilops spp., which are considered an important part of the secondary gene pool for wheat $(10,27)$. Interspecific hybrids within the Sitopsis group show full or nearly full chromosome pairing and are either fertile or semifertile (28).

The Sitopsis group of Aegilops spp. includes five diploid species: A. speltoides, which is thought to be the donor for the $\mathrm{B}$ genome in wheat, A. bicornis, A. longissima, A. sharonensis, and A. searsii. Wild populations of all five species occur naturally in Israel. Two closely related tetraploid species, A. kotschyi and A. variabilis, which also are found in Israel, contain the $\mathrm{S}$ and $\mathrm{U}$ genomes. Another tetraploid species in Israel, A. ovata, has the $\mathrm{U}$ and $\mathrm{M}$ genomes and has been found to hybridize occasionally with $A$. variabilis in nature (15). The objectives of this research were to sample wild populations of these eight species of Aegilops in Israel and to test the accessions as potential sources of new genes for resistance to leaf rust, stem rust, and stripe rust.

\section{MATERIALS AND METHODS}

Seed were collected from 1,323 single plants representing eight Aegilops spp. from natural populations at 83 sites in 18 regions of Israel as well as 1 region in southern Lebanon and 1 region in Egypt adjacent to Israel (Tables 1 and 2). Seed of single plant accessions were increased through two to five generations in screen houses and nurseries at Tel Aviv. All accessions are deposited in the Lieberman Germplasm Bank, Institute for Cereal Crops Improvement, Tel Aviv University. Accessions of Aegilops spp. were grown in a field nursery at Tel Aviv where they were
Table 1. Numbers of accessions (Acc.) of Aegilops spp. tested for rust resistance and source regions of collections in Israel and adjacent regions of Egypt and Lebanon

\begin{tabular}{|c|c|c|c|c|c|c|}
\hline \multirow[b]{2}{*}{ Aegilops sp. $(\text { genome })^{\mathrm{a}}$} & \multicolumn{2}{|c|}{ Greenhouse, Israel } & \multicolumn{2}{|c|}{ Field, Israel } & \multicolumn{2}{|c|}{ Greenhouse, Minnesota } \\
\hline & Acc. & Regions & Acc. & Regions & Acc. & Regions \\
\hline A. bicornis $(\mathrm{S})$ & 19 & 2 & 21 & 2 & 11 & 2 \\
\hline A. kotschyi (SU) & 29 & 5 & 37 & 5 & 0 & 0 \\
\hline A. longissima $(\mathrm{S})$ & 476 & 5 & 502 & 5 & 379 & 5 \\
\hline A. ovata $(\mathrm{UM})$ & 125 & 8 & 98 & 8 & 91 & 7 \\
\hline A. searsii $(\mathrm{S})$ & 88 & 2 & 91 & 2 & 59 & 2 \\
\hline A. sharonensis (S) & 257 & 3 & 230 & 3 & 0 & 0 \\
\hline A. speltoides $(\mathrm{S})$ & 194 & 5 & 200 & 5 & 181 & 4 \\
\hline A. variabilis (SU) & 128 & 11 & 144 & 11 & 137 & 10 \\
\hline
\end{tabular}

${ }^{a}$ Species designated S are diploids in the Sitopsis group within the genus Aegilops; species with SU or UM genomes are tetraploid. The $\mathrm{S}$ genome is closely related to the B genome of cultivated wheat. 
inoculated with bulk collections of $P$. striiformis and $P$. triticina obtained from wild and cultivated wheat lines in Israel. Most accessions also were tested for seedling resistance to leaf rust or stem rust in greenhouses at Tel Aviv and at the United States Department of Agriculture-Agricultural Research Service, Cereal Disease Laboratory in St. Paul, MN.

Tel Aviv tests. Accessions of Aegilops spp. were planted in November in single 1$\mathrm{m}$ rows in a field nursery at Tel Aviv. Spreader rows of a leaf rust-susceptible wheat cultivar were inoculated by spraying with a suspension of urediniospores of $P$. triticina and $P$. striiformis in light mineral oil (Soltrol 170) in February. Leaf rust inoculum consisted of a bulk uredinial population of $P$. triticina derived from aeciospores from leaves of Thalictrum speciosissimum. The basidiospores that infected the T. speciosissimum plants were produced by incubating the plants with germinating teliospores from collections of telia obtained from naturally infected cultivated and wild wheat plants at multiple locations throughout Israel. Stripe rust inoculum consisted of a bulk uredinial population of $P$. striiformis collected from cultivated and wild wheat plants at multiple locations in Israel. The accessions of Aegilops spp. in the nursery were evaluated twice for leaf rust and stripe rust severity and reaction type in late April and early May. General reaction types (i.e., $\mathrm{S}=$ susceptible, $\mathrm{R}=$ resistant, $\mathrm{MR}=$ moderately resistant, and so on) also were recorded for each accession.

In the greenhouse at Tel Aviv, 1,316 accessions of Aegilops spp. also were tested for seedling resistance to $P$. triticina and two forms of $P$. recondita. Inocula for these three forms of leaf rust consisted of uredinial populations of: (i) P. triticina derived from aeciospores from $T$. speciosissimum, the alternate host for wheat leaf rust; (ii) the A. longissima form of $P$. recondita derived from aeciospores from Anchusa aggregata, the alternate host for leaf rust of Aegilops longissima; and (iii) the $A$. ovata form of $P$. recondita derived from aeciospores from Echium glomeratum, the alternate host for leaf rust of $A$. ovata. For each of the three leaf rusts, the aecial populations were obtained by exposing the alternate host to a collection of leaves of the appropriate host with abundant telia that had been pretreated to induce germination of the teliospores (1). Telial collections of $P$. triticina on cultivated wheat and telial collections of $P$. recondita on wild populations of Aegilops spp. were obtained from multiple locations throughout Israel. Thus, each aecial population was a representative sample of the virulence diversity within Israel.

For seedling tests with each form of leaf rust, four accessions were planted per pot with four seed per accession and grown in a temperature-controlled greenhouse at $20 \pm$ $2^{\circ} \mathrm{C}$. At 7 to 10 days after planting, the seedlings were inoculated with urediniospores of $P$. triticina or $P$. recondita. Seedlings were sprayed with a suspension of urediniospores in light mineral oil (Soltrol 170), the oil was allowed to evaporate, and the inoculated plants were incubated overnight in a dew chamber before being returned to the greenhouse. At 12 to 14 days after inoculation, the plants were scored for infection type (IT) on a standard 0-to-4 scale (17). ITs of 0 to 2 were considered resistant, ITs of 3 to 4 were considered susceptible, and ITs scored as 2,3 or 3,2 (i.e., with mixtures of IT2 and IT3 uredinia) were considered less than fully susceptible.

St. Paul tests. In St. Paul, 858 accessions of six of the eight Aegilops spp. were tested for seedling resistance to leaf rust in three tests and for resistance to stem rust in two tests (Table 1). In the first two seedling tests for leaf rust resistance, plants were inoculated with single isolates of race TBBL and race SBDB of $P$. triticina, which were common in the United States. In the third leaf rust test, the seedlings were inoculated with a composite of 12 races (BBGL, CBGB, DBBG, KDBL, MFBL, MGBL, PBRG, PLMQ, PQRS, SBDJ, TBBL, and TLGG), all of which had been isolated from wheat fields in the United States. Virulence formulas for these races are derived as described in Long et al. (18). In the first seedling test for stem rust resistance, plants were inoculated with a single isolate of race TPMK of $P$. graminis $\mathrm{f}$. sp. tritici, which had been the most common wheat stem rust race in the Untied States for many years. In the second stem rust test, the seedlings were inoculated with a composite of four common races: QCCJ, QFCS, RCRS, and TPMK.

In each test, seed of the accessions to be inoculated were grown in vermiculite in 8$\mathrm{cm}^{2}$ plastic pots with three to five seed each of four accessions planted in the corners of each pot. Glumes were removed from the seed before planting. The pots were arranged in trays holding six pots each, and the plants were grown in a rustfree greenhouse for 7 days before inoculation. The seedlings were fertilized at 5 and 8 days after planting with a water-soluble fertilizer (23-19-17, NPK) at $2.5 \mathrm{~g} /$ tray. On the seventh day after planting, the seedlings were inoculated by spraying them with a suspension of urediniospores in light mineral oil. The oil was allowed to evaporate for $30 \mathrm{~min}$, and the inoculated seedlings were placed in a dew chamber overnight at $18^{\circ} \mathrm{C}$. For stem rust, the dew chamber was programmed for fluorescent

Table 2. Regions from which accessions of Aegilops spp. were collected

\begin{tabular}{|c|c|c|c|c|c|c|c|c|}
\hline \multirow[b]{2}{*}{ Region } & \multicolumn{8}{|c|}{ No. of sites with indicated Aegilops sp. ${ }^{\mathrm{a}}$} \\
\hline & bic & kot & lon & ova & sea & sha & spe & var \\
\hline Southern Lebanon & $\ldots$ & $\ldots$ & $\ldots$ & 2 & $\ldots$ & $\ldots$ & $\ldots$ & $\ldots$ \\
\hline Haifa Bay & $\ldots$ & $\ldots$ & $\ldots$ & $\ldots$ & $\ldots$ & 1 & $\ldots$ & $\ldots$ \\
\hline Mt. Carmel & $\ldots$ & $\ldots$ & $\ldots$ & 4 & $\ldots$ & $\ldots$ & 2 & 1 \\
\hline Upper Galilee & $\ldots$ & $\ldots$ & $\ldots$ & 7 & $\ldots$ & $\ldots$ & $\ldots$ & 2 \\
\hline Eastern Upper Galilee & $\ldots$ & $\ldots$ & $\ldots$ & 1 & $\ldots$ & $\ldots$ & $\ldots$ & 2 \\
\hline Golan Heights & $\ldots$ & $\ldots$ & $\ldots$ & $\ldots$ & $\ldots$ & $\ldots$ & $\ldots$ & 1 \\
\hline Mt. Hermon & $\ldots$ & $\ldots$ & $\ldots$ & 2 & $\ldots$ & $\ldots$ & $\ldots$ & $\ldots$ \\
\hline Plateau of Menashe & $\ldots$ & $\ldots$ & $\ldots$ & $\ldots$ & $\ldots$ & $\ldots$ & $\ldots$ & 1 \\
\hline Valley of Esdraelon & $\ldots$ & $\ldots$ & $\ldots$ & $\ldots$ & $\ldots$ & $\ldots$ & 1 & $\ldots$ \\
\hline Samaria & $\ldots$ & $\ldots$ & $\ldots$ & 1 & $\ldots$ & $\ldots$ & 1 & 1 \\
\hline Coast of Carmel & $\ldots$ & $\ldots$ & $\ldots$ & $\ldots$ & $\ldots$ & $\ldots$ & 12 & 2 \\
\hline Central Coastal Plain & $\ldots$ & $\ldots$ & 13 & 1 & $\ldots$ & 9 & $\ldots$ & 7 \\
\hline Southern Coastal Plain & $\ldots$ & $\ldots$ & 1 & $\ldots$ & $\ldots$ & 3 & 2 & 3 \\
\hline Southern Coastal Plain (Egypt) & 3 & $\ldots$ & $\ldots$ & $\ldots$ & $\ldots$ & $\ldots$ & $\ldots$ & $\ldots$ \\
\hline Judean Desert & $\ldots$ & 1 & $\ldots$ & $\ldots$ & 1 & $\ldots$ & $\ldots$ & $\ldots$ \\
\hline Judean Foothills & $\ldots$ & $\ldots$ & $\ldots$ & $\ldots$ & $\ldots$ & $\ldots$ & $\ldots$ & 1 \\
\hline Judean Mts. & $\ldots$ & 3 & $\ldots$ & 1 & 3 & $\ldots$ & $\ldots$ & 1 \\
\hline Negev Mts. & $\ldots$ & 5 & 1 & $\ldots$ & $\ldots$ & $\ldots$ & $\ldots$ & $\ldots$ \\
\hline Northern Negev & 7 & 1 & 2 & $\ldots$ & $\ldots$ & $\ldots$ & $\ldots$ & $\ldots$ \\
\hline Western Negev & $\ldots$ & 5 & 2 & $\ldots$ & $\ldots$ & $\ldots$ & $\ldots$ & $\ldots$ \\
\hline
\end{tabular}

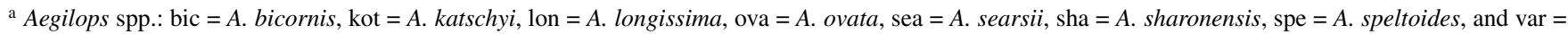
A. variabilis. 
lights to turn on for 3 to $4 \mathrm{~h}$ before the dew chamber was opened to allow the seedlings to dry slowly for $2 \mathrm{~h}$ while the temperature rose gradually to $25^{\circ} \mathrm{C}$. When dry, the plants were returned to the greenhouse, where temperatures varied between 18 and $28^{\circ} \mathrm{C}$ daily. At 12 to 14 days after inoculation, the plants were scored for IT as described for greenhouse tests at Tel Aviv.

\section{RESULTS}

Accessions of Aegilops spp. were obtained from 18 different regions of Israel and from adjacent regions of Egypt and southern Lebanon. The most widely collected species was A. variabilis from 11 regions, and the most restricted species were $A$. searsii and A. sharonensis from 2 and 3 regions, respectively, and $A$. bicornis from the Southern Coastal Plain and Northern Negev of Israel and the adjacent region of Egypt (Table 2).

Field tests. In field trials, all accessions of A. ovata and A. speltoides remained largely free of stripe rust: no accessions of these species had greater than 5\% severity of stripe rust (Table 3). Most accessions of A. longissima and $A$. variabilis had only 1 or $2 \%$ stripe rust severity, although a few accessions of each species had severities of as much as $30 \%$ or more. All accessions of A. bicornis and all but one accession of $A$. kotschyi had stripe rust severities of $20 \%$ or more. Accessions of A. searsii and A. sharonensis ranged from highly resistant to highly susceptible to stripe rust, with mean severity values in the intermediate range for the Aegilops spp. tested. Mean severities of leaf rust in field plots were low for all eight species, but only A. kotschyi had no susceptible accessions (Table 3). Of the 200 accessions of A. speltoides, 2 had leaf rust severity of 20 and $30 \%$; the other 198 had only $1 \%$ severity. There was essentially no correlation between stripe rust and leaf rust severities on accessions of any of the Aegilops spp. tested in the field (Table 3).

For A. bicornis, A. longissima, A. ovata, A. searsii, A. sharonensis, and A. spel- toides, accessions collected from different regions did not differ appreciably in mean stripe rust severity in the field tests. Accessions of A. kotschyi from four regions had mean stripe rust severity values from 40 to $58 \%$, but the four accessions from the Judean Desert averaged $75 \%$ severity. Due to the small numbers of accessions of $A$. kotschyi, these differences were not statistically significant. Accessions of A. variabilis from Samaria and Upper Galilee averaged 1.0 and $1.1 \%$ severity, respectively, whereas mean stripe rust severity values for the other five regions ranged from 5 to $12 \%$. Mean stripe rust severities for accessions from Samaria and Upper Galilee were significantly lower $(P<0.05$, $t$ test) than severities for accessions from the Central Coastal Plain, Golan Heights, or the Southern Coastal Plain.

Mean leaf rust severity values in field tests were similar among regions for accessions of A. bicornis, A. kotschyi, A. searsii, and A. speltoides. Accessions of A. longissima from the Central Coastal Plain were most resistant to leaf rust, with mean severity of $3.8 \%$. Accessions from the Negev Mountains with mean severity of $23.4 \%$ were significantly $(P<0.05, t$ test $)$ more susceptible than accessions from the other four regions. Severity values for the Northern Negev, Western Negev, and Southern Coastal Plain ranged from 6 to $12 \%$. Accessions of $A$. ovata from all but two regions had low mean leaf rust severities $(<7 \%)$. There was only one A. ovata accession each from the Central Coastal Plain and Samaria and each was susceptible, with severity values of 40 and $20 \%$, respectively. The 6 accessions of A. sharonensis from the Haifa Bay region averaged $25.7 \%$ leaf rust severity, whereas the 183 accessions from the Central Coastal Plain averaged $2.3 \%$ and the 41 accessions from the Southern Coastal Plain averaged $2.1 \%$ leaf rust severity. Because there were only six accessions from the Haifa Bay region and because their severities ranged from 1 to $80 \%$, the differences between regions for $A$. sharonensis were not statistically significant. The five accessions of A. variabilis from the Plateau of Menashe averaged $16 \%$ leaf rust severity, which was significantly greater $(P<0.05 . t$ test $)$ than the mean severities for accessions from the six other regions. The 15 accessions from Upper Galilee averaged only $1.2 \%$, which was significantly $(P<0.05, t$ test $)$ less than the mean severities for accessions of $A$. variabilis from any other region. Four accessions of A. variabilis from Mt. Carmel, Eastern Upper Galilee, and the Judean Mountains also were all highly resistant ( $<2 \%$ severity). Accessions from the Central Coastal Plain, Golan Heights, Judean Foothills, Samaria, and Southern Coastal Plain averaged from 2.4 to $5.7 \%$ leaf rust severity.

Greenhouse seedling tests, Tel Aviv. The population of $P$. recondita derived from $E$. glomeratum in Israel was virulent to $95 \%$ of the accessions of $A$. ovata but avirulent on all accessions of the other seven Aegilops spp. except for A. variabilis, in which $98 \%$ of the accessions were resistant and $2 \%$ had mixed susceptible and resistant reactions to the Echium population of $P$. recondita (Table 4). All or nearly all of the accessions of A. bicornis, A. kotschyi, A. longissima, A. searsii, A. sharonensis, and $A$. variabilis were susceptible to the population of $P$. recondita derived from Anchusa aggregata, which is not virulent to common wheat. All of the accessions of Aegilops speltoides and most accessions from $A$. ovata were resistant to P. recondita from Anchusa spp. (Table 4).

All eight Aegilops spp. had some accessions that were susceptible to the population of $P$. triticina derived from $T$. speciosissimum in Israel (Table 4). Aegilops speltoides was the most resistant, with only $1 \%$ of the accessions susceptible to $P$. triticina. A. longissima, A. sharonensis, and $A$. variabilis had good resistance with $25 \%$ or less the accessions showing full susceptibility as seedlings. A. bicornis, A. kotschyi, A. ovata, and A. searsii were

Table 3. Response of accessions (acc.) of Aegilops spp. to Puccinia striiformis and P. triticina in field plots at Tel Aviva

\begin{tabular}{|c|c|c|c|c|c|c|c|c|}
\hline \multirow[b]{3}{*}{ Species } & \multirow[b]{3}{*}{ No. of acc. } & \multicolumn{3}{|c|}{ P. striiformis } & \multicolumn{3}{|c|}{ P. triticina } & \multirow[b]{3}{*}{ Corr. $^{d}$} \\
\hline & & \multirow[b]{2}{*}{$\operatorname{Res}(\%)^{b}$} & \multicolumn{2}{|c|}{ Severity (\%) } & \multirow[b]{2}{*}{$\operatorname{Res}(\%)^{b}$} & \multicolumn{2}{|c|}{ Severity (\%) } & \\
\hline & & & Meanc $^{c}$ & Range & & Meanc $^{c}$ & Range & \\
\hline A. bicornis & 19 & 0 & $41.6 \pm 4.2$ & $20-80$ & 0 & $4.3 \pm 2.1$ & $2-20$ & -0.055 \\
\hline A. kotschyi & 37 & 3 & $48.2 \pm 4.8$ & $2-90$ & 91 & $1.3 \pm 0.7$ & $0-2$ & nd \\
\hline A. longissima & 512 & 91 & $3.6 \pm 2.5$ & $1-30$ & 97 & $7.1 \pm 3.3$ & $1-60$ & -0.053 \\
\hline A. ovata & 142 & 99 & $1.1 \pm 0.7$ & $1-5$ & 82 & $4.4 \pm 2.6$ & $1-40$ & nd \\
\hline A. searsii & 91 & 18 & $23.8 \pm 3.5$ & $1-40$ & 91 & $5.7 \pm 3.4$ & $1-80$ & 0.146 \\
\hline A. sharonensis & 239 & 57 & $15.0 \pm 4.2$ & $1-80$ & 96 & $2.9 \pm 3.1$ & $0-80$ & 0.035 \\
\hline A. speltoides & 200 & 100 & $1.0 \pm 0.3$ & $1-2$ & 99 & $1.2 \pm 1.6$ & $1-30$ & nd \\
\hline A. variabilis & 144 & 77 & $6.3 \pm 3.1$ & $1-60$ & 96 & $4.9 \pm 2.3$ & $1-20$ & -0.003 \\
\hline
\end{tabular}

${ }^{\text {a }}$ Field plots were inoculated with bulks of isolates of $P$. striiformis and $P$. triticina from cultivated and wild wheat plants collected throughout Israel.

b Percentage of accessions with resistance ratings of very resistant, resistant, or moderately resistant based on size and appearance of uredinia. For $A$. kotschyi, 16 accessions were so severely infected by P. striiformis that no readings could be obtained for $P$. triticina; all but 2 of the remaining 21 accessions were rated resistant or moderately resistant to $P$. triticina.

c Mean severity \pm standard error.

${ }^{\mathrm{d}}$ Coefficients of correlation between severity ratings for $P$. striiformis and $P$. triticina on each accession; nd indicates that no correlation was calculated due to limited variation in severity ratings for one or both rusts. 
mostly susceptible; fewer than $10 \%$ of the accessions of those species showed resistant or mixed reactions (Table 4).

In most cases, the proportions of accessions resistant or susceptible to $P$. triticina in the seedling stage did not differ greatly among regions from which the accessions were collected. With A. longissima, A. sharonensis, and A. variabilis, however, some regional differences were found. In A. longissima, greatest percentage of resistant accessions, $78 \pm 7 \%$ (95\% confidence interval), was found in the Negev Mountains and the least resistance, $14 \pm 19 \%$, was found in the Southern Coastal Plain. Percentages of resistant accessions from other regions were Central Coastal Plain, $50 \pm 4 \%$; Northern Negev, $58 \pm 9 \%$; and Western Negev, $60 \pm 19 \%$. With A. sharonensis, $67 \pm 5 \%$ of the accessions from the Central Coastal Plain, $54 \pm 10 \%$ from the Southern Coastal Plain, and $33 \pm 27 \%$ from the Haifa Bay region were resistant. With A. variabilis, high levels of resistance were found in Upper Galilee (100\%), the Judean Foothills $(86 \pm 19 \%)$, the Plateau of Menashe $(75 \pm 30 \%)$, and the Central Coastal Plain $(61 \pm 8 \%$ ), whereas only 22 $\pm 19 \%$ of the accessions from the Golan Heights were resistant to $P$. triticina.

Greenhouse seedling tests, St. Paul. All of the accessions of $A$. speltoides tested as seedlings in St. Paul were resistant to races SBDB and TBBL and the composite inoculum of $P$. triticina, but all of the accessions of $A$. bicornis were susceptible (Table 5). Most accessions of $A$. variabilis
(74 to 88\%) and some of the accessions of A. longissima ( 37 to $39 \%$ ) and A. ovata (30 to $33 \%$ ) also were resistant as seedlings to the U.S. isolates of $P$. triticina. Few accessions of A. searsii (5 to 6\%) were resistant to race SBDB or the composite inoculum of $P$. triticina, but $18 \%$ were resistant to race TBBL (Table 5 ).

In A. longissima, the greatest resistance occurred in accessions from the Negev Mountains $(81 \pm 10 \%)$, whereas none of the accessions from the Southern Coastal Plain was resistant to either race or the composite inoculum. With A. variabilis, most of the accessions from Upper Galilee $(79 \pm 15 \%)$, the Judean Foothills (75 \pm $30 \%)$, the Plateau of Menashe (100\%), and the Central Coastal Plain $(83 \pm 6 \%)$ were resistant to the composite inoculum. Less resistance occurred among accessions from the Golan Heights $(43 \pm 26 \%)$ and the Southern Coastal Plains (65 $\pm 15 \%)$. There were too few accessions from other regions for reliable comparisons. Proportions of accessions of $A$. variabilis resistant to races SBDB and TBBL generally were similar to those resistant to the composite inoculum, although a small percentage of accessions showed different reactions to the three inocula. Accessions of A. kotschyi and $A$. sharonensis were not tested in St. Paul.

All of the accessions of $A$. speltoides were resistant to $P$. graminis f. sp. tritici as seedlings in greenhouse tests in St. Paul (Table 6). On the other hand, 95 to $96 \%$ of $A$. searsii accessions were susceptible. Accessions of A. bicornis, A. longissima,

Table 6. Seedling reactions of accessions of Aegilops spp. from Israel to North American isolates of Puccinia graminis f. sp. tritici $i^{\mathrm{a}}$

\begin{tabular}{lccccccc}
\hline & \multicolumn{3}{c}{ Race TPMK } & & \multicolumn{3}{c}{ Composite $^{\text {b }}$} \\
\cline { 2 - 3 } Host species & Res (\%) & Mixed (\%) & Susc (\%) & & Res (\%) & Mixed (\%) & Susc (\%) \\
\hline A. bicornis & $50 \pm 22$ & 5 & 45 & & $24 \pm 18$ & 24 & 52 \\
A. longissima & $34 \pm 5$ & 15 & 51 & & $32 \pm 5$ & 21 & 48 \\
A. ovata & $44 \pm 11$ & 20 & 36 & & $36 \pm 19$ & 12 & 52 \\
A. searsii & $5 \pm 6$ & 0 & 95 & & $4 \pm 5$ & 0 & 96 \\
A. speltoides & 100 & 0 & 0 & & 100 & 0 & 0 \\
A. variabilis & $51 \pm 8$ & 3 & 46 & & $44 \pm 15$ & 40 & 16 \\
\hline
\end{tabular}

a Results of greenhouse tests in St. Paul, MN; 95\% confidence intervals for percent resistant accessions were calculated by the normal approximation method (26); for values of 0 or $100 \%$, no confidence interval can be determined. Res = resistant, Mixed = resistant and susceptible combined, Susc $=$ susceptible.

${ }^{\mathrm{b}}$ Composite of four races of $P$. graminis f. sp. tritici collected in field surveys in the United States: QCCJ, QFCS, RCRS, and TPMK.

Table 4. Seedling reactions of accessions of Aegilops spp. from Israel to leaf rust fungi from three aecial hosts ${ }^{\mathrm{a}}$

\begin{tabular}{|c|c|c|c|c|c|c|c|c|c|}
\hline \multirow[b]{2}{*}{ Host species } & \multicolumn{3}{|c|}{ Thalictrum $^{\mathrm{b}}$} & \multicolumn{3}{|c|}{ Anchusa $^{\mathrm{c}}$} & \multicolumn{3}{|c|}{ Echium $^{\mathrm{c}}$} \\
\hline & $\operatorname{Res}(\%)$ & Mixed (\%) & Susc $(\%)$ & $\operatorname{Res}(\%)$ & Mixed (\%) & $\operatorname{Susc}(\%)$ & $\operatorname{Res}(\%)$ & Mixed (\%) & $\operatorname{Susc}(\%)$ \\
\hline A. bicornis & $5 \pm 10$ & 0 & 95 & 0 & 0 & 100 & 100 & 0 & 0 \\
\hline A. kotschyi & $7 \pm 9$ & 0 & 93 & 0 & 0 & 100 & 100 & 0 & 0 \\
\hline A. longissima & $55 \pm 4$ & 29 & 16 & $1 \pm 1$ & 0 & 99 & 100 & 0 & 0 \\
\hline A. ovata & $5 \pm 4$ & 3 & 92 & $82 \pm 7$ & 5 & 13 & $5 \pm 4$ & 0 & 95 \\
\hline A. searsii & $2 \pm 3$ & 0 & 98 & 0 & 1 & 99 & $99 \pm 2$ & 1 & 0 \\
\hline A. sharonensis & $64 \pm 6$ & 11 & 25 & $1 \pm 1$ & 2 & 97 & 100 & 0 & 0 \\
\hline A. speltoides & $96 \pm 3$ & 3 & 1 & 100 & 0 & 0 & 100 & 0 & 0 \\
\hline A. variabilis & $59 \pm 8$ & 20 & 20 & 0 & 0 & 100 & $98 \pm 3$ & 2 & 0 \\
\hline
\end{tabular}

${ }^{a}$ Results of greenhouse tests at Tel Aviv; 95\% confidence intervals for percent resistant accessions were calculated by the normal approximation method (26); for values of 0 or $100 \%$, no confidence interval can be determined. Res $=$ resistant, Mixed $=$ resistant and susceptible combined, Susc $=$ susceptible.

${ }^{\mathrm{b}}$ Leaf rust caused by Puccinia triticina.

c Leaf rust caused by Puccinia recondita.

Table 5. Seedling reactions of accessions of Aegilops spp. from Israel to North American isolates of Puccinia triticina ${ }^{\mathrm{a}}$

\begin{tabular}{|c|c|c|c|c|c|c|c|c|c|}
\hline \multirow[b]{2}{*}{ Host species } & \multicolumn{3}{|c|}{ Race SBDB } & \multicolumn{3}{|c|}{ Race TBBL } & \multicolumn{3}{|c|}{ Composite $^{b}$} \\
\hline & $\operatorname{Res}(\%)$ & Mixed (\%) & Susc $(\%)$ & $\operatorname{Res}(\%)$ & Mixed (\%) & Susc $(\%)$ & $\operatorname{Res}(\%)$ & Mixed (\%) & Susc $(\%)$ \\
\hline A. bicornis & 0 & 0 & 100 & 0 & 0 & 100 & 0 & 0 & 100 \\
\hline A. longissima & $39 \pm 6$ & 21 & 40 & $39 \pm 5$ & 18 & 43 & $37 \pm 5$ & 29 & 34 \\
\hline A. ovata & $32 \pm 10$ & 7 & 61 & $33 \pm 10$ & 10 & 57 & $30 \pm 10$ & 25 & 45 \\
\hline A. searsii & $5 \pm 7$ & 26 & 68 & $18 \pm 10$ & 11 & 71 & $6 \pm 6$ & 8 & 87 \\
\hline A. speltoides & 100 & 0 & 0 & 100 & 0 & 0 & 100 & 0 & 0 \\
\hline A. variabilis & $88 \pm 6$ & 2 & 10 & $79 \pm 7$ & 7 & 14 & $74 \pm 7$ & 5 & 21 \\
\hline
\end{tabular}

a Results of greenhouse tests in St. Paul, MN; 95\% confidence intervals for percent resistant accessions were calculated by the normal approximation method (26); for values of 0 or $100 \%$, no confidence interval can be determined. Res $=$ resistant, Mixed = resistant and susceptible combined, Susc $=$ susceptible.

${ }^{\text {b }}$ Composite of 12 races of $P$. triticina collected in field surveys in the United States: BBGL, CBGB, DBBG, KDBL, MFBL, MGBL, PBRG, PLMQ, PQRS, SDBJ, TBBL, and TLGG. 
A. ovata, and A. variabilis were nearly equally divided between resistant and susceptible, although many accessions exhibited mixed ITs to race TPMK or the composite inoculum of $P$. graminis f. sp. tritici (Table 6). Accessions of A. kotschyi and A. sharonensis were not tested for stem rust resistance. No clear regional differences in proportions of accessions resistant to stem rust were seen for $A$. biornis, A. ovata, A. searsii, or A. speltoides. With A. longissima, no resistant accession was found from the Negev Mountains, Northern Negev, Western Negev, or the Southern Coastal Plain, but $51 \pm 5 \%$ of the accessions from the Central Coastal Plain were resistant to race TPMK and $49 \pm 4 \%$ were resistant to the composite inoculum of $P$. graminis f. sp. tritici. With A. variabilis, $74 \pm 14 \%$ of the accessions from the Southern Coastal Plain, $50 \pm 8 \%$ from the Central Coastal Plain, and $13 \pm 16 \%$ from the Golan Heights were resistant to race TPMK of $P$. graminis f. sp. tritici. Accessions from regions other than the Central Coastal Plain were not tested against the composite inoculum; $44 \pm 10 \%$ of the accessions from the Central Coastal Plain were resistant to the composite.

\section{DISCUSSION}

The Aegilops spp. evaluated in this research compose a rich and varied source of potential new genes for rust resistance genes for wheat breeding (16). Hundreds of accessions were identified with resistance to leaf rust, stripe rust, or stem rust. Collection information and rust reaction data for all of the accessions are available on request from the Lieberman Germplasm Bank at the Institute for Cereal Crops Improvement, Tel Aviv University. Seed of selected accessions also may be obtained from the Lieberman Germplasm Bank.

Among the five Aegilops spp. in the Sitopsis group, which have the $\mathrm{S}$ genome, there was a wide range of susceptibility to the rust diseases. Nearly all accessions of A. speltoides were resistant to leaf rust and stripe rust in field tests and to leaf rust and stem rust in seedling tests in the greenhouse. A. longissima and A. sharonensis also appear to be good sources of rust resistance, although A. sharonensis was not tested for stem rust resistance. In contrast, nearly all accessions of $A$. bicornis were susceptible to leaf rust and stripe rust, and nearly all accessions of $A$. searsii were susceptible to leaf rust and stem rust in seedling tests. Most accessions of A. searsii, however, appeared to have good adult plant resistance to leaf rust and stripe rust, but $A$. bicornis accessions were susceptible to both rusts. All of the Aegilops spp. tested except A. searsii had moderate to high proportions of accessions that were resistant to stem rust in seedling tests. These results are consistent with earlier, less extensive studies in Israel $(11,19,23)$ and generally also are consistent with stud- ies of the same Aegilops spp. from other countries $(4,6,12,22,25)$. One exception was the apparent high level of resistance in A. bicornis accessions to leaf rust in field tests in India (4). Also, Salazar and Branas (25) reported that the A. bicornis accessions that they tested were resistant to stem rust in Portugal.

The high level of resistance of A. speltoides to leaf rusts in Israel is especially interesting. Anchusa and Echium spp., the alternate hosts for $P$. recondita, are native to Israel; therefore, it is logical to assume a long history of coevolution between $P$. recondita and Aegilops bicornis, A. longissima, A. searsii, and A. sharonensis, all of which have limited distributions centered in Israel or, in the case of A. bicornis, extending from the Israeli Negev west along the coastal sandy steppe of North Africa. The distribution of $A$. speltoides, on the other hand, includes much of the Near East and Anatolia with its southernmost populations in Israel, where A. speltoides is relatively rare and found mainly on the alluvial soils of the coastal belt and Mt. Carmel (28). Thalictrum spp., the alternate host of $P$. triticina, do not occur in Israel. It may be a result of this that relatively few accessions of A. longissima or A. sharonensis and almost none of $A$. speltoides were susceptible to isolates of $P$. triticina from wheat. It seems odd, however, that a rare forma specialis of $P$. triticina that is virulent to $A$. speltoides but avirulent to cultivated wheat was discovered in Israel and is unknown elsewhere (3).

Among the three tetraploid species evaluated, A. kotschyi appeared to have good adult plant resistance but little seedling resistance to leaf rust. Most accessions of $A$. variabilis were resistant to leaf rust and stripe rust, and about half were resistant to stem rust. A. ovata, which is more distantly related to common wheat than the other Aegilops spp. tested, also may be a good source of resistance to stripe rust, stem rust and, perhaps, to U.S. races of leaf rust.

It is interesting that A. longissima, A. sharonensis, and $A$. variabilis, which had high proportions of accessions with seedling resistance to leaf rust caused by $P$. triticina, showed little or no resistance to the endemic leaf rust caused by $P$. recondita (aecial host Anchusa spp.) in Israel. Aegilops ovata was largely resistant to $P$. recondita from Anchusa spp. but susceptible to its leaf rust caused by $P$. recondita (aecial host Echium spp.) as well as to $P$. triticina. Apparently, natural selection in Israel has resulted in an accumulation of virulence genes in $P$. recondita (aecial host Anchusa spp.) to match the resistance genes in A. longissima, A. sharonensis, and A. variabilis, whereas natural selection in $P$. recondita (aecial host Echium spp.) resulted in accumulation of virulence genes to match the resistance genes in $A$. ovata but not those in other Aegilops spp.
Nearly all accessions of $A$. speltoides were resistant to both forms of $P$. recondita as well as to races of $P$. triticina commonly found on wheat.

Even though nearly all accessions of $A$. speltoides were highly resistant to $P$. triticina, A. speltoides has an underlying compatibility to wheat leaf rust, as shown by the one accession with full susceptibility in seedling tests at Tel Aviv and the two accessions that developed severe leaf rust infection as adult plants in field tests. This underlying compatibility also is evidenced by the discovery of a new form of $P$. triticina in Israel that is virulent on most accessions of A. speltoides, A. bicornis, A. longissima, A. searsii, and A. sharonensis but avirulent to bread wheat cultivars (3). Apparently, the high level of resistance to wheat leaf rust in A. speltoides is due to a variety of major genes for hypersensitive, race-specific resistance for which the corresponding virulence alleles are largely absent in populations of $P$. triticina on common wheat in Israel and the United States. Five known leaf rust resistance genes, $L r 28, L r 35, L r 36, L r 47$, and $L r 51$, have been transferred to bread wheat from A. speltoides $(9,14,20,21)$. In addition, uncharacterized leaf rust resistance genes have been transferred to wheat from four other accessions of A. speltoides $(8,20)$. Thus, it appears likely that numerous additional genes for leaf rust resistance for use in wheat breeding could be found in accessions of A. speltoides described in this research.

In transferring genes for rust resistance from wild species to cultivated species, the goal is to maximize the chances that the new resistance genes will be unique as well as highly effective against known rust races. With no known rust races with specific virulence to distinguish between new resistance genes, laborious genetic tests will be necessary to confirm that the new resistance genes really are different from previously isolated resistance genes that are also effective against all known rust races. To reduce the chances of repeatedly transferring the same genes from Aegilops spp. to common wheat, it will be useful to choose donor accessions from several different Aegilops spp. as well as from geographically separated collections within species. Our results provide some guidance for selection of sites and Aegilops spp. from which to select accessions for crosses for gene transfer to wheat.

There were no obvious associations between elevation and yearly rainfall for individual collection sites and the proportion of resistant accessions of Aegilops spp. obtained per site. Accessions of $A$. kotschyi from the Judean Desert were more susceptible to stripe rust than accessions from other regions of Israel, including those from the Negev, which has even less rainfall than the Judean Desert. The proportion of accessions of A. longissima 
from the Negev Mountains with seedling resistance to leaf rust in both the Tel Aviv and St. Paul greenhouse tests was greater than that from other regions with greater rainfall, but accessions from the Negev Mountains developed more severe leaf rust than accessions from any other region as adult plants in field plots. Conversely, accessions of $A$. variabilis from the $\mathrm{Me}-$ nashe Plateau (with greater rainfall) were more susceptible to leaf rust as adult plants in field tests than accessions from the Southern Coastal Plain (with less rainfall), but accessions from the Menashe Plateau were less susceptible to leaf rust as seedlings in the greenhouse. Accessions of $A$. sharonensis from the Haifa Bay region were more susceptible to leaf rust than accessions from the Central or Southern Coastal Plain, as both seedlings in the greenhouse and adult plants in field tests. The average annual rainfall of sites in the Southern Coastal Plain was less than that in the Haifa Bay site, but annual rainfall in the Central Coastal Plain sites was nearly the same as at Haifa Bay. There were few interregional differences in proportions of accessions of Aegilops spp. resistant to stem rust, but accessions of $A$. variabilis from the Golan Heights (greatest annual rainfall) were considerably more susceptible than accessions from other regions of Israel. It seems likely that long-term stand density of Aegilops populations may be a more critical determinant of local epidemic development of rust diseases than differences in temperature or rainfall from region to region in Israel. This could lead to evolution of greater rust resistance in sites where each species of Aegilops is best adapted and where their populations have been allowed to reach their greatest density.

Each of the Aegilops spp. evaluated in this study can serve as a donor for rust resistance genes for wheat breeding. For example, leaf rust and stripe rust resistance have been transferred to common wheat, Triticum aestivum, from $A$. ovata, a species that does not share a common genome with common wheat (5). Ittu et al. (13) reported the transfer of a gene for leaf rust resistance from the tetraploid species $A$. variabilis to common winter wheat. Among the five species in the Sitopsis group, only A. speltoides has been used as a source of leaf rust and stem rust resistance in current wheat cultivars (20). However, the powdery mildew resistance gene Pm13 was transferred to common wheat from A. longissima (10). Our results suggest that $A$. longissima and $A$. sharonensis also could be rich sources of genes for resistance to leaf rust and stripe rust. Zhang et al. (27) showed that there is a high degree of conserved colinearity in chromosomes of the $\mathrm{S}$ genomes of A. longissima and A. sharonensis and the D genome of common wheat. Thus, transfer of resistance from these species should not be much more difficult than transferring resistance genes from A. speltoides to common wheat.

\section{LITERATURE CITED}

1. Anikster, Y. 1986. Teliospore germination in some rust fungi. Phytopathology 76:1026-1030.

2. Anikster, Y., Bushnell, W. R., Eilam, T., Manisterski, J., and Roelfs, A. P. 1997. Puccinia recondita causing leaf rust on cultivated wheats, wild wheats, and rye. Can. J. Bot. 75:2082-2096.

3. Ben Yehuda, P., Eilam, T., Manisterski, J., Shimoni, A., and Anikster. Y. 2004. Leaf rust on Aegilops speltoides caused by a new forma specialis of Puccinia triticina. Phytopathology 94:94-101.

4. Dhaliwal, H. S., Harjit-Singh, Gupta, S., Bagga, P. S., and Gill, K. S. 1991. Evaluation of Aegilops and wild Triticum species for resistance to leaf rust (Puccinia recondita $\mathrm{f}$. sp. tritici) of wheat. Int. J. Trop. Agric. 9:118-122.

5. Dhaliwal, H. W., Harjit-Singh, and Williams, M. 2002. Transfer of rust resistance from Aegilops ovata into bread wheat (Triticum aestivum $\mathrm{L}$.) and molecular characterization of resistant derivatives. Euphytica 126:152-159.

6. Dimov, A., Zaharieva, M., and Mihova, S. 1993. Rust and powdery mildew resistance in Aegilops accessions from Bulgaria. Pages 165169 in: Biodiversity and Wheat Improvement. A. B. Damania, ed. John Wiley, New York.

7. Dubcovsky, J., Lukaszewski, A. J., Echaide, M., Antonelli, E. F., and Porter, D. R. 1998. Molecular characterization of two Triticum speltoides interstitial translocations carrying leaf rust and greenbug resistance genes. Crop Sci. 38:1655-1660.

8. Dvorak, J. 1977. Transfer of leaf rust resistance from Aegilops speltoides to Triticum aestivum. Can. J. Genet. Cytol. 19:133-141.

9. Dvorak, J., and Knott, D. R. 1990. Location of a Triticum speltoides chromosome segment conferring resistance to leaf rust in Triticum aestivum. Genome 33:892-897.

10. Friebe, B, Jiang, J., Raupp, W. J., McIntosh, R. A., and Gill, B. S. 1996. Characterization of wheat-alien translocations conferring resistance to diseases and pests: current status. Euphytica 91:59-87.

11. Gerechter-Amitai, Z. K., and Loegering, W. Q. 1977. Genes for low reaction to Puccinia graminis tritici in Aegilops and Triticum. Crop Sci. 17:830-832.

12. Gill, B. S., Sharma, H. C., Raupp, W. J., Browder, L. E., Hatchett, J. H., Harvey, T. L., Moseman, J. G., and Waines, J. G. 1985. Evaluation of Aegilops species for resistance to wheat powdery mildew, wheat leaf rust, Hes- sian fly, and greenbug. Plant Dis. 69:314-316.

13. Ittu, M., Giura, A., Ittu, G., and Saulescu, N. N. 1996. Test of allelism for a resistance gene to leaf rust transferred to common wheat from Aegilops variabilis L. Cereal Rusts and Powdery Mildews Bull. Vol. 24(Suppl.):3.5.

14. Kerber, E. R., and Dyck, P. L. 1990. Transfer to hexaploid wheat of linked genes for adultplant leaf rust resistance and seedling stem rust resistance from an amphiploid of Aegilops speltoides $\times$ Triticum monococcum. Genome 33:530-537.

15. Kimber, G., and Feldman, M. 1987. Wild Wheat: An Introduction. Special Report 353 College of Agriculture, University of MissouriColumbia.

16. Knott, D. R. 1989. The Wheat Rusts-Breeding for Resistance. Monographs on Theoretical and Applied Genetics 12, Springer-Verlag, Berlin.

17. Long, D. L., and Kolmer, J. A. 1989. A North American system of nomenclature for Puccinia recondita f. sp. tritici. Phytopathology 79:525-529.

18. Long, D. L., Kolmer, J. A., Leonard, K. J., and Hughes, M. E. 2002. Physiologic specialization of Puccinia triticina on wheat in the United States in 2000. Plant Dis. 86:981-986.

19. Manisterski, J., Segal, A., Levy, A. A., and Feldman, M. 1988. Evaluation of Israeli Aegilops and Agropyron species for resistance to wheat leaf rust. Plant Dis. 72:941-946.

20. McIntosh, R. A., Wellings, C. R., and Park, R. F. 1995. Wheat Rusts: An Atlas of Resistance Genes. Kluwer Academic Publishers, London.

21. McIntosh, R. A., Yanazoki, Y., Devos, K. M. Dubcovsky, J., Rogers, W. J., and Appels, A. 2003. Catalogue of gene symbols for wheat. In Proc. Int. Wheat Genet. Sympos. 10th. Paestum, Italy. Vol. 4. N. E. Pogna, ed. CD version.

22. Pasquini, M. 1980. Disease resistance in wheat: II. Behavior of Aegilops species with respect to Puccinia recondita f. sp. tritici, Puccinia graminis f. sp. tritici, and Erysiphe graminis f. sp. tritici. Genet. Agric. 34:33-148.

23. Rothschild, H., Manisterski, J., and Anikster, Y. 1988. Reaction of Triticum dicoccoides populations and several Aegilops species to Israeli isolates of Puccinia recondita tritici. (Abstr.) Phytoparasitica 16:77-78.

24. Saari, E. E., and Prescott, J. M. 1985. World distribution in relation to economic losses. Pages 259-298 in: The Cereal Rusts, vol. II. A. P. Roelfs and W. R. Bushnell, eds. Academic Press, Orlando, FL.

25. Salazar, J., and Branas, M. 1968. The reaction of Aegilops spp. to several leaf and stem rust races. Pages 52-52 in: Proc. Cereal Rusts Conf Oeiras, Portugal. Tip. Anuerio Commercical de Portugal.

26. Steel, R. G. D., and Torrie, J. H. 1960. Principles and Procedures of Statistics. McGrawHill, New York.

27. Zhang, H., Reader, S. M., Liu, X., Jia, J. Z., and Gale, M. D. 2001. Comparative genetic analysis of the Aegilops longissima and Ae. sharonensis genomes with common wheat. Theor. Appl. Genet. 103:518-525.

28. Zohary, D. 1983. Wild genetic resources of crops in Israel. Isr. J. Bot. 32:97-129. 